\title{
Molecular and Biochemical Characterization of Potential Isolates of Trichoderma Species Effective against Soil-Borne Pathogens
}

\author{
N. Srinivasa ${ }^{1 *}$, Deeba Kamil ${ }^{1}$, Chandu Singh, Avinash Singode $^{3}$ and Deeksha Gupta ${ }^{1}$ \\ ${ }^{1}$ Division of Plant Pathology, ${ }^{2}$ Seed Production Unit, ICAR-Indian Agricultural Research \\ Institute, New Delhi, India \\ ${ }^{4}$ ICAR-Indian Institute of Millet Research, Hyderabad, India \\ *Corresponding author:
}

\section{A B S T R A C T}

\section{Keywords}

Biochemical,

Molecular,

Hydrolytic enzymes,

Trichoderma

harzianum,

Trichoderma virens,

Soil-borne

pathogens.

Article Info

Accepted:

29 May 2017

Available Online:

10 June 2017
Trichoderma species is one of the key potential bio-control agents against soil-borne pathogens. In this study molecular and biochemical characterization were done using twenty four potential isolates of Trichoderma species, based on internal transcribed spacer (ITS $1 \& 4)$, translation elongation factor(tef-1) gene region and hydrolytic enzymes. In this studytef-1 was found to be better than ITS, to distinguish the Trichoderma isolates into two different species viz., Trichoderma virens and Trichoderma harzianum, on the basis of maximum parsimony sequence analysis. The specific activity of the hydrolytic enzymes showed the significance difference between both the species of Trichoderma, tested against three different pathogens such as Fusarium oxysporum, Rhizoctonia solani and Sclerotiumrolfsii. It was also found that cultivation of Trichoderma isolates with soil borne pathogen (during interaction) produced high hydrolytic enzymes compared to Trichoderma species alone. Among the potential isolates tested for enzyme assay, three isolates viz., V7, V-19 and V-21 of $T$. virens and three isolates such as $\mathrm{H}-10, \mathrm{H}-12$ and $\mathrm{H}-21$ of $T$. harzianum were found as high potential isolates based on its specific activity of the hydrolytic enzymes. Therefore, the identified isolates could be effectively used as potential bio-control agents against soil-borne plant pathogens.

\section{Introduction}

Trichoderma spp. Is one of the widespread saprophytic fungi in rhizosphere, which have received considerable attention as potential bio-control agents against most of plant pathogens as well as high utility towards medical and industrial sciences. The advent of molecular era could be judiciously utilized for investigations in fungal taxonomy prompted research in the mid-nineties to re-assess the morphology based taxonomy in Trichoderma (Druzhinina et al., 2005). Only morphological attributes are not enough to define the species of Trichoderma used against plant pathogens.
The authentic identification of Trichoderma facilitates the researchers for definitive taxonomy.

The internal transcribed spacer (ITS-1) and internal transcribed spacer (ITS-2) region of $5.8 \mathrm{Sr}$ DNA and tef-1 (gene) of the five Trichoderma virens isolates were analyzed (Chaverri et al., 2001). Hermosa et al., 2004, attempted to analyze the genetic variability within bio-control isolates of Trichoderma using sequence data obtained from the ITS 
region of the nuclear rDNA and a fragment of translation elongation factor gene (tef -1 alpha). There are various mechanisms encompass in Trichoderma antagonism, such as competition, mycoparasitism and antibiosis etc., whereby the antagonistic fungus shows production of antibiotics. In case of mycoparasitism, Trichoderma directly attack the plant pathogens by excreting various lytic enzymes such as cellulase, chitinase, $\beta-1,3$ glucanases, proteases, poly-galacturanase (PG), pectin esterase, depolymerase, endoxylanase $\quad(1,4 \quad \beta$-D-xylanxylanohydrolase) etc, these enzymes involved in the degradation of cell wall which leads tolysis of hyphae of the pathogen. The skeleton of pathogenic fungi cell wallencompass chitin, glucan, pectin, xylan and cellulose enzymes that are hydrolyse these components have to be present in the successful antagonists in order to play a significant role in cell wall lysis of the pathogen (Chernin et al., 2002; Kubicek et al., 2001; Viterbo et al., 2002).

The present investigation was an attempt for the effective utilization of the molecular and biochemical methods based on hydrolytic enzymes, to select potential isolates against soil-borne pathogens. This can help in the improvement and enhancement of bio-control strain and comprehend their mechanism of protection against soil-borne pathogens.

\section{Materials and Methods}

\section{Molecular confirmation based on ITS and} tef-1 regions

Twenty-four isolates of Trichoderma (Table 1) were molecularly characterized and analyzed for their hydrolytic enzymes production. The molecular characterization based on DNA sequencing of two unlinked loci, the ribosomal ITS region and the teflgene (White et al., 1990). The tef- 1 fragment was amplified by PCR using the specific primers (Geiser et al., 2004; Hermosa et al.,
2004) (Table 1). The DNA was extracted using modified C-TAB method and PCR product was performed and analyzed through 1.2 agarose gel electrophoresis. Purified PCR products were sequenced separately in an automated ABI 3100 Genetic Analyser (Applied Biosystem, USA) by Bangalore Genei (Bangalore, India). Homologies to known sequences were searched in gene bank database using the Basic Alignment Search Tool (BLAST) available online from the National Centre for Biotechnology Information (NCBI). Phylogenetic analyses were performed using MEGA5 (Tamura et $a l ., 2011)$ and a parsimony analysis tree was constructed using the Kimura-2- parameter distance model (Kimura, 1980).

\section{Biochemical characterization of Trichoderma isolates based on hydrolytic enzymes}

For biochemical characterization a total of twenty four isolates of Trichoderma (Table 3) (without interaction and during the interaction with $F$. oxysporum, $R$. solani and $S$. rolfsii) were used, to study various hydrolytic enzymes (cellulase, $\beta-1,3$ glucanase, $\beta-1,4$ glucanase, chitinase and protease). All the Trichoderma isolates were grown in a minimal synthetic medium (MSM), (11) supplemented with different substrates as sole carbon sources. The $50 \mathrm{ml}$ medium was inoculated with Trichoderma isolates with pathogens $\left(2 \mathrm{X} 10^{8} \mathrm{cfu} / \mathrm{ml}\right)$, in interaction studies and no pathogens were inoculated in, without interaction studies. Enzyme activity was expressed in specific activity as IU/ mg protein. The protein estimation in culture supernatants of each treatment was followed by the method of Bradford (1976).

\section{Enzyme assay}

\section{Cellulase (E.C. 3.2.1.4)}

The assay mixture contained $1 \mathrm{ml}$ of $0.5 \%$ cellulose (Sigma Co.) suspended in 50Mm 
$(0.05 \mathrm{M})$ citrate phosphate buffer $(\mathrm{pH} 4.8)$ and $1 \mathrm{ml}$ of culture filtrates of various Trichoderma strains in $15 \mathrm{ml}$ test tubes. The reaction mixture was incubated for 30 minute at $50^{\circ} \mathrm{C}$. The blanks were made using distilled water in place of culture filtrate. The absorbance was measured at $540 \mathrm{~nm}$ and the amount of reducing sugar released was calculated with standard curve of glucose (Miller, 1959).

\section{B-1, 3 glucanase (E.C. 3.2.1.58)}

ß-1, 3 glucanase was assayed similarly by incubating $1 \mathrm{ml} 0.2 \%$ laminarin (w/v) in 50 Mm sodium acetate buffer ( $\mathrm{pH} 4.8)$ with $1 \mathrm{ml}$ enzyme solution at $40^{\circ} \mathrm{C}$ for $1 \mathrm{hr}$ and by determining the reducing sugars with DNS (Nelson, 1944).

\section{B-1, 4 glucanase (exoglucanase)}

(E.C.3.2.1.91)

A mixture of $1 \mathrm{ml}$ of $1.0 \%$ carboxymethyl cellulose, $2.0 \mathrm{ml}$ of $0.05 \mathrm{M}$ citrate buffer $(\mathrm{pH}$ 4.8) and $1.0 \mathrm{ml}$ culture filtrate, incubated at $55^{\circ} \mathrm{C}$ for 30 minute in water bath with periodical shaking. The reaction was stopped by boiling and adding of $4.0 \mathrm{ml}$ of dinitrosalicyclic acid reagent and the said enzyme activity was estimated (Thrane et al., 2000).

\section{Chitinase (E.C. 3.2.1.14)}

The reaction mixture prepared with $0.5 \mathrm{ml}$ suspension of colloidal chitin (0.5\%), $1.0 \mathrm{ml}$ Mcllvaine's buffer ( $\mathrm{pH}$ 4.0) and $0.5 \mathrm{ml}$ culture filtrate (enzyme source), this was mixed thoroughly and incubated at $37^{\circ} \mathrm{C}$ for 20 minute in water bath with periodical shaking.

The reaction was stopped by boiling the mixture for 3 minute in boiling water bath. $3.0 \mathrm{ml}$ potassium ferric cyanide reagent was added and warmed in boiling water bath for 15 minute. The amount of N-acetyl glucosamine (NAG) released was calculated from the absorbance of reaction mixture at $420 \mathrm{~nm}$. The activity of chitinase was expressed as IU/mg (Sahai et al., 1993).

\section{Protease (Tyrosinase-E.C.1.14.18.1)}

The substrate used $(1 \%$ casein in $50 \mathrm{Mm}$ phosphate buffer, $\mathrm{pH}$ 7.0) was denatured at $100^{\circ} \mathrm{C}$ for 15 minute in water bath and cooled at room temperature. The reaction-mixture containing $1 \mathrm{ml}$ of substrate and $1 \mathrm{ml}$ of enzyme solution was incubated at $37^{0} \mathrm{C}$ for 20 minute and the reaction was stopped with adding $3 \mathrm{ml}$ of $10 \%$ tri-chloro acetic acid (TCA). The tubes were allowed to stand for 1 hour at $4^{0} \mathrm{C}$ to allow undigested protein to precipitate. The absorbance of liberated tyrosine in the filtrate was measured at 280 nm (Yang et al., 1994).

Grouping of Trichoderma virens and Trichodermaharzianum isolates on the basis of specific activity of enzymes against soilborne pathogens

Twenty four isolates of Trichoderma were evaluated for their potentiality to produce various extracellular enzymes. The isolates were categorized into three groups based on their specific activity of enzymesviz., Group1: (>20 IU/mg) high,Group-2: (10-20 IU/mg) moderate and Group-3: (0-10 IU/mg) low specific activity of potential isolates respectively.

\section{Statistical analysis}

The data were analyzed using pair-t test to differentiate the significance of results of enzyme activities.

\section{Results and Discussion}

Molecular identification of Trichoderma isolates based on ITS $1 \& 4$ and tef-1 regions: A total of twenty four isolates of Trichoderma species were used for the 
molecular confirmation based on their ITS and tef-1 nucleotide sequences (Table 2).

\section{PCR amplication and sequencing}

Successful PCR amplifications were done using ITS $1 \& 4$ and tef- 1 primers in twenty four isolates of Trichoderma species. A PCR product size was obtained as 600-650 bp for ITS $1 \& 4$ and 900-950 bp for tef- 1 based on sequence analysis (Figs.1 and 2). All the distance values were calculated using the Kimura 2-parameter distance algorithm (Mega-5 software) and the obtained sequences were submitted to NCBI database.

\section{Molecular phylogenetic analysis}

To elucidate the genetic closeness of the twenty four isolates of Trichoderma phylogenetic tree was constructed based on sequence analysis of ITS $1 \& 4$ and tef- 1 regions using the maximum parsimony analysis method using Mega $5.2 \mathrm{v}$.

A random sequence of other species of Trichoderma was used in the present study for out-group as to demonstrate the situation of the root and to comparison with Trichoderma virens and Trichoderma harzianum isolates. Phylogenetic analysis of ITS region revealed that there are three major clusters present, but this region could not differentiate the Trichoderma isolates in different groups with the bootstrap value ranging from $64-100 \%$ (Fig.3). But, the phylogenetic analysis based on tef- 1 sequences revealed that there are three major clusters.

The cluster I contained all the isolates of $T$. harzianum (14 isolates) was supported with a bootstrap value higher than 65\%along with other species such as $T$. longibrachiatum (2 isolates), $T$. pseudokoningii (2 isolates) and $T$. reesei (2 isolates). The cluster II and III comprised the Trichoderma virens (10 isolates) is supported with a bootstrap value of $92 \%$ and $77 \%$, respectively (Fig.4).

\section{Biochemical characterization of} Trichoderma isolates

The investigation was focused on biochemical characterization of Trichoderma isolates by production of hydrolytic enzymes such as cellulase, ß-1, 3-glucanase, ß-1, 4-glucanase, chitinase and protease (Table 3). These enzymes specifically involved for degradation of cell wall of the pathogen, which intern helps in understanding the mechanism of biological control activity and selecting of potential isolates of Trichoderma species against soil-borne pathogens. The perusal of entire results revealed that the 08 potential isolates of $T$. virens and 12 potential isolates of $T$. harzianum significantly produced various hydrolytic enzymes without any interaction with soil borne pathogen.

However, among the $T$. virens isolates inoculated with sole carbon source without any interaction with soil-borne pathogens, the isolates $\mathrm{V}-19 \quad(21.85 \mathrm{IU} / \mathrm{mg}) / \mathrm{V}-17 \quad(14.02$ $\mathrm{IU} / \mathrm{mg}), \mathrm{V}-19$ (18.19 IU/mg) $/ \mathrm{V}-21 \quad(18.00$ $\mathrm{IU} / \mathrm{mg}), \mathrm{V}-7$ (18.85 IU/mg) / V-19 (17.10 $\mathrm{IU} / \mathrm{mg}), \mathrm{V}-7$ (19.68 IU/mg) / V-17 (18.01 $\mathrm{IU} / \mathrm{mg})$ and $\mathrm{V}-19$ (16.01 IU/mg) / V-21 (15.27 IU/mg) showed highest production of hydrolytic enzymes activity viz., cellulose, $\beta$ 1,3 glucanase, $\beta-1,4$ glucanase, chitinase and protease respectively whereas, the isolates, $\mathrm{V}$ 4 (6.17 IU/mg) / V-18 (6.80 IU/mg), V-4 (4.08 IU/mg) / V-18 (5.86 IU/mg), 18 (5.05 $\mathrm{IU} / \mathrm{mg})$ / V-22 (6.15 IU/mg), V-4 (9.16 $\mathrm{IU} / \mathrm{mg}) / \mathrm{V}-18$ (9.25 IU/mg) and V-4 (3.88 $\mathrm{IU} / \mathrm{mg})$ and $\mathrm{V}-18 \quad(4.26 \mathrm{IU} / \mathrm{mg})$ showed lowest production of hydrolytic enzymes activity viz., cellulose, $\beta-1,3$ glucanase, $\beta-1,4$ glucanase, chitinase and protease respectively. Similarly, among the $T$. harzianum, the isolates H-10/ H-12 (18.64 $\mathrm{IU} / \mathrm{mg}) / \mathrm{H}-21$ (16.35 IU/mg), H-10 (13.16 $\mathrm{IU} / \mathrm{mg}) / \mathrm{H}-12$ (10.41 IU/mg), H-12 (17.95 $\mathrm{IU} / \mathrm{mg}$ ) / H-10 (12.06 IU/mg), H-10 (34.63 $\mathrm{IU} / \mathrm{mg}) / \mathrm{H}-26$ (25.34 IU/mg) and H-21 
(18.56 IU/mg) / H-10 (18.05 IU/mg) showed highest production of hydrolytic enzymes activity viz., cellulose, $\beta-1,3$ glucanase, $\beta-1,4$ glucanase, chitinase and protease respectively whereas, the isolates, H-24 (7.43 IU/mg) / H6 (8.33 IU/mg), H-24 (4.33 IU/mg) / H-6 (5.42 IU/mg), H-6 (4.16 IU/mg) / H-24 (5.73 IU/mg), H-6 (5.91 IU/mg) / H-2 (8.82 IU/mg) and H-6 (4.92 IU/mg) / H-24 (6.03 IU/mg) showed lowest production of hydrolytic enzymes activity viz., cellulose, $\beta-1,3$ glucanase, $\beta-1,4$ glucanase, chitinase and protease respectively (Table 4 ).

Further, it was also observed that interaction between Trichoderma with soil-borne pathogens ( $F$. oxysporum, $R$. solani and $S$. rolfsii) were also produced various hydrolytic enzymes. When the $T$. virens and $T$. harzianum isolates interacted with soil-borne pathogens, during their interaction all the isolates showed increased production of the hydrolytic enzymes (Table 5).

The isolates of $T$. virens during antagonism with Fusarium oxysporum interactions showed significant production in all the enzymes. The isolate V-7 (34.88 IU/mg) / V21 (26.91 IU/mg), V-19 (19.56 IU/mg) / V-8 (13.45 IU/mg), V-19 (19.28 IU/mg) / V-7 (18.22 IU/mg), V-17 (30.13 IU/mg) / V-23 (24.37 IU/mg) and V-19 (19.44 IU/mg) / V-7 $(18.94 \mathrm{IU} / \mathrm{mg})$ showed highest production of hydrolytic enzymes activity viz., cellulose, $\beta$ 1,3 glucanase, $\beta-1,4$ glucanase, chitinase and protease respectively whereas, the isolates, $\mathrm{V}$ 18 (7.55 IU/mg) / V-4 (8.41 IU/mg), V-4 (6.03 IU/mg) / V-18 (7.41 IU/mg), V-18 (7.28 IU/mg) / V-4 (7.57 IU/mg), V-4 (8.57 $\mathrm{IU} / \mathrm{mg}) / \mathrm{V}-18$ (9.89 IU/mg) and V-4 (2.60 $\mathrm{IU} / \mathrm{mg}) / \mathrm{V}-18$ (6.21 IU/mg) showed lowest production of hydrolytic enzymes activity viz., cellulose, $\beta-1,3$ glucanase, $\beta-1,4$ glucanase, chitinase and protease respectively.
During antagonism with Rhizoctonia solani, isolate V-7 (42.11 IU/mg), V-19 (31.40 $\mathrm{IU} / \mathrm{mg})$ / V-7 (16.20 IU/mg),V-19 (12.29 $\mathrm{IU} / \mathrm{mg}) / \mathrm{V}-19$ (19.28 IU/mg), V-17 (11.89 $\mathrm{IU} / \mathrm{mg})$ / V-17 (38.73 IU/mg), V-7 (33.29 $\mathrm{IU} / \mathrm{mg}$ ) and V-21 (18.48 IU/mg), V-7 (18.29 $\mathrm{IU} / \mathrm{mg}$ ) showed highest production of hydrolytic enzymes activity viz., cellulose, $\beta$ 1,3 glucanase, $\beta-1,4$ glucanase, chitinase and protease respectively whereas, the isolates, $\mathrm{V}$ 4 (8.83 IU/mg), V-18 (10.38 IU/mg) / V-4 (4.06 IU/mg), V-18 (7.14 IU/mg) / V-23 (4.83 IU/mg), V-18 (5.93 IU/mg) / V-18 (11.28 IU/mg), V-4 (12.16 IU/mg) / V-4 (4.19 $\mathrm{IU} / \mathrm{mg})$ and $\mathrm{V}-18(7.44 \mathrm{IU} / \mathrm{mg})$ showed lowest production of hydrolytic enzymes activity viz., cellulose, $\beta-1,3$ glucanase, $\beta-1,4$ glucanase, chitinase and protease respectively.

Similarly, with Sclerotium rolfsii the isolates, V-19 (30.31 IU/mg), V-21 (16.75 IU/mg) / V19 (19.01 IU/mg),V-21 (16.46 IU/mg) / V-21 (19.43 IU/mg), V-19 (16.79 IU/mg) / V-19 (24.21 IU/mg), V-21 (22.71 IU/mg) / V-7 (18.50 IU/mg), V-21 (18.20 IU/mg) showed highest production of hydrolytic enzymes activity viz., cellulose, $\beta-1,3$ glucanase, $\beta-1,4$ glucanase, chitinase and protease respectively whereas, the isolates, V-4 (7.71 IU/mg), V-18 (8.49 IU/mg) / V-4 (4.06 IU/mg), V-18 (6.20 $\mathrm{IU} / \mathrm{mg})$ / V-18 (7.89 IU/mg), V-9 (8.30 $\mathrm{IU} / \mathrm{mg})$ / V-18 (11.81 IU/mg), V-22 (12.24 $\mathrm{IU} / \mathrm{mg}$ ) and $\mathrm{V}-4$ (3.29 IU/mg), V-18 (4.87 IU/mg) showed lowest production of hydrolytic enzymes activity viz., cellulose, $\beta$ 1,3 glucanase, $\beta-1,4$ glucanase, chitinase and protease respectively.

However, among the $T$. harzianum isolates inoculated with sole carbon source with $F$. oxysporum interaction showed significant production in all the enzymes. The isolates, H-12 (20.83 IU/mg), H-7 (18.88 IU/mg) / H18 (13.90 IU/mg), H-21 (13.03 IU/mg) / H-12 (15.35 IU/mg), H-28 (13.34 IU/mg) / H-10 
(83.78 IU/mg), H-3 (49.29 IU/mg) / H-2 (16.32 IU/mg), H-21 (14.20 IU/mg) showed highest production of hydrolytic enzymes activity viz., cellulose, $\beta-1,3$ glucanase, $\beta-1,4$ glucanase, chitinase and protease respectively whereas, the isolates, H-6 (7.99 IU/mg), H24 (9.15 IU/mg) / H-6 (7.91 IU/mg), H-24 (9.25 IU/mg) / H-6 (6.42 IU/mg), H-24 (8.20 $\mathrm{IU} / \mathrm{mg})$ / H-6 (10.84 IU/mg), H-24 (15.37 $\mathrm{IU} / \mathrm{mg}$ ) and $\mathrm{H}-24$ (8.17 IU/mg), H-7 (8.83 $\mathrm{IU} / \mathrm{mg}$ ) showed lowest production of hydrolytic enzymes activity viz., cellulose, $\beta$ 1,3 glucanase, $\beta-1,4$ glucanase, chitinase and protease respectively.

During antagonism with Rhizoctonia solani interaction showed the isolates, H-12 (52.07 $\mathrm{IU} / \mathrm{mg})$, H-7 (28.82 IU/mg) / H-12 (16.44 $\mathrm{IU} / \mathrm{mg}), \mathrm{H}-10(15.90 \mathrm{IU} / \mathrm{mg}) / \mathrm{H}-12$ (13.70 $\mathrm{IU} / \mathrm{mg}), \mathrm{H}-7$ (13.32 IU/mg) / H-10 (62.63 $\mathrm{IU} / \mathrm{mg}), \mathrm{H}-2(51.72 \mathrm{IU} / \mathrm{mg})$ and $\mathrm{H}-10(31.37$ $\mathrm{IU} / \mathrm{mg}), \mathrm{H}-12$ (21.90 IU/mg) showed highest production of hydrolytic enzymes activity viz., cellulose, $\beta-1,3$ glucanase, $\beta-1,4$ glucanase, chitinase and protease respectively whereas, the isolates, H-24 (5.23 IU/mg), H-6 (9.39 IU/mg) / H-6 (6.50 IU/mg), H-24 (8.39 IU/mg) / H-24 (7.01 IU/mg), H-6 (7.71 IU/mg) / H-24 (16.93 IU/mg), H-6 (18.87 $\mathrm{IU} / \mathrm{mg}$ ) and $\mathrm{H}-6$ (4.84 IU/mg), H-7 (6.27 $\mathrm{IU} / \mathrm{mg}$ ) showed lowest production of hydrolytic enzymes activity viz., cellulose, $\beta$ 1,3 glucanase, $\beta-1,4$ glucanase, chitinase and protease respectively.

Similarly with Sclerotiumrolfsii, the isolate H-18 (29.22 IU/mg), H-3 (26.31 IU/mg) / H21 (18.78 IU/mg), H-12 (18.09 IU/mg) / H-21 (22.42 IU/mg), H-12 (19.59 IU/mg) / H-10 (88.80 IU/mg), H-12 (43.56 IU/mg) and $\mathrm{H}-$ 10 and $\mathrm{H}-12$ (23.88 IU/mg), H-26 (16.17 $\mathrm{IU} / \mathrm{mg}$ ) showed highest production of hydrolytic enzymes activity viz., cellulose, $\beta$ 1,3 glucanase, $\beta-1,4$ glucanase, chitinase and protease respectively whereas, the isolates, $\mathrm{H}$ 24 (7.44 IU/mg), H-6 (8.74 IU/mg) / H-6
(6.17 IU/mg), H-24 (8.67 IU/mg) / H-24 (8.31 $\mathrm{IU} / \mathrm{mg}), \mathrm{H}-18$ (8.62 IU/mg) / H-6 (12.74 $\mathrm{IU} / \mathrm{mg}), \mathrm{H}-24$ (14.99 IU/mg) and H-6 (7.78 $\mathrm{IU} / \mathrm{mg}), \mathrm{H}-24(9.45 \mathrm{IU} / \mathrm{mg})$ showed lowest production of hydrolytic enzymes activity viz., cellulose, $\beta-1,3$ glucanase, $\beta-1,4$ glucanase, chitinase and protease respectively.

Grouping of Trichoderma virens and Trichoderma harzianum isolates on the basis of specific activity of enzymes against soil-borne pathogens

Twenty four isolates of Trichoderma were evaluated for their potentiality to produce various extracellular enzymes against three soil-borne plant pathogens. All the isolates were categorized into different groups based on their enzymes activity as Group-1: (>20 IU/mg)-High, Group-2: (10-20 IU/mg)Moderate and Group-3: (0-10 IU/mg)-Low potential. It was also inferred that the most of isolates appeared under moderate as well as low potential groups and very few isolates appeared under high potential in both with and without interaction with the pathogens (Table 6).

With the above investigation it was found that, V-7, V-19 and V-21 of T. virens have high potential isolates and V-4 was considered as low potential isolate. Similarly, the isolates $\mathrm{H}-10, \mathrm{H}-12$ and $\mathrm{H}-21$ of $T$. harzianum have high potential and the isolate H-6 was considered as low potential.

The advent of molecular technology would help in molecular characterization of potential Trichoderma strains and could help for taxonomic identification. For molecular characterization, there is a need of precise molecular data resulting from DNA sequencing (Samuels, 2006). The internal transcribed spacer (ITS) and tef- 1 regions of the ribosomal DNA (rDNA) are the most 
reliable targets to identify a strain at the species level (19). In this way, combination of both (ITS and tef-1)region, allow most identifications at the species level. Use of two unlinked loci (ITS and tef-1), further helped in molecular identification, where it was difficult to conclude with the ITS region alone. It can be concluded that the combined approach of morphological and molecular techniques are necessary for authentic identification of Trichoderma strains.

A total of twenty four isolates of Trichoderma spp. were used in present investigation to analyze various hydrolytic enzyme activities as well as molecular characterization based on their ITS and tef- 1 nucleotide sequences of $T$. virens and $T$. harzianum. The Phylogenetic tree, based on ITS didnot clearly separated the species but tef-1 gene analysis showed separation of Trichoderma isolates into $T$. virens and $T$. harzianum. Therefore, the tef- 1 region could be a better tool for differentiation of both the species. The findings are matching with the observations made by Samuels, 2006. It was reported that Trichoderma secretes hydrolytic enzymes at a constitutive level and detects the presence of another fungus by sensing the molecules released from the host with enzymatic degradation (Lorito et al., 2006). The antifungal arsenals of Trichoderma spp encompass a great variety of lytic enzymes (Lorito et al., 1993, 1996, 1998) and most of enzymes play key role in bio-control (Harman et al., 1998; Baek et al., 1999; Carsolio et al., 1999; Woo et al., 1999; Zeilinger et al., 1999; Kulling et al., 2000; Vinale et al., 2008).

In the present investigation, twenty four isolates of Trichoderma species were evaluated for their potentiality to produce various extracellular enzymes against three soil-borne plant pathogens, viz., $F$. oxysporum, $R$. solani and $S$. rolfsii and based on high potentiality of isolates was utilized for subsequent studies. Present findings are consistent with the earlier findings (Mach et al., 1999; El-Katatny et al., 2001, 2004) where they were reported that the addition of some carbon sources in growth medium with and without interaction of soilborne pathogens significantly improved the secretion of certain cell wall degrading enzymes. In the present investigation, 10 isolates of $T$. virens and 14 isolates of $T$. harzianum produced different hydrolytic enzymes (cellulase, $\beta-1,3$ glucanase, $\beta-1,4$ glucanase, chitinase and protease) when the basal medium (minimal synthetic media) was supplemented with different carbon sources and soil-borne pathogens ( $F$. oxysporum, $R$. solani and $S$. rolfsii). The extracellular enzymes activity was observed in all the isolates and they were categorized into different groups based on their specific enzyme activity.

Table.1 Primers used for amplification of ITS $1 \& 4$ and tef-1 gene regions

\begin{tabular}{|c|c|c|}
\hline Region & Primer sequence & Reference \\
\hline ITS1-5.8S-ITS2 region of rDNA & $\begin{array}{c}\text { ITS-1: } \\
\text { 5'- TCCGTAGGTGAACCTGCGG-3' } \\
\text { ITS-4: } \\
\text { 5'-TCCTCCGCTTATTGATATGC-3' }\end{array}$ & (2) \\
\hline $\begin{array}{c}\text { Intron } \mathrm{b} / \mathrm{w} 5 \text { thand } 6^{\text {th }} \text { exon of } t e f- \\
1 \text { region }\end{array}$ & $\begin{array}{c}t e f-1 \mathrm{fw}: \\
\text { 5'-GTGAGCGTGGTA-TCACCA-3' } \\
\text { tef- } 1 \text { rev: } \\
\text { 5'GCCATCCTTGGAGACCAGC-3' }\end{array}$ & (3) \\
\hline
\end{tabular}


Table.2 Molecular confirmation of Trichoderma isolates by using ITS and tef-1 region

\begin{tabular}{|c|c|c|c|c|c|c|c|}
\hline \multirow{2}{*}{$\begin{array}{l}\text { Name of the } \\
\text { isolates/ } \\
\text { Strain No. }\end{array}$} & \multirow{2}{*}{ Accession No. } & \multirow{2}{*}{ Sources } & \multicolumn{2}{|c|}{ Origin } & \multicolumn{2}{|c|}{ NCBI GeneBank accession numbers } & \multirow{2}{*}{$\begin{array}{c}\text { Morphological/ } \\
\text { Molecular/ Definitive } \\
\text { identification }\end{array}$} \\
\hline & & & Place & State & ITS & tef-1 & \\
\hline V-4 & ITCC-6470 & Soil & Pusa & Bihar & KF144619 & KF668101 & T. virens \\
\hline V-7 & ITCC-6411 & Soil & Barrackpur & West Bengal & KF144622 & KF668104 & T. virens \\
\hline V-8 & MTCC-749 & Soil & Pantnagar & Uttarakhand & KF144623 & KF668105 & T. virens \\
\hline V-9 & MTCC-1373 & Soil & Pantnagar & Uttarakhand & KF144624 & KF668106 & T. virens \\
\hline V-17 & MTCC-2977 & Soil & Kolkata & West Bengal & KF144632 & KF668114 & T. virens \\
\hline V-18 & MTCC-2979 & Soil & Kolkata & West Bengal & KF144633 & KF668115 & $T$. virens \\
\hline V-19 & MTCC-2983 & Soil & Kolkata & West Bengal & KF144634 & KF668116 & T. virens \\
\hline V-21 & MTCC-4346 & Soil & Almora & Uttarakhand & KF144636 & KF668118 & T. virens \\
\hline V-22 & ITCC-7351 & Soil & Kozhikode & Kerala & KF144637 & KF668119 & T. virens \\
\hline V-23 & ITCC-7352 & Soil & Kozhikode & Kerala & KF144638 & KF668120 & T. virens \\
\hline $\mathbf{H}-2$ & ITCC-4950 & Soil & New Delhi & Delhi & KF144640 & KF668122 & T. harzianum \\
\hline H-3 & ITCC-5223 & Compost & New Delhi & Delhi & KF144641 & KF668123 & T. harzianum \\
\hline H-6 & ITCC-6797 & Soil & Bengaluru & Karnataka & KF144644 & KF668126 & T. harzianum \\
\hline H-7 & ITCC-6888 & Rhizosphere Soil & Navasari & Gujarat & KF144645 & KF668127 & T. harzianum \\
\hline H-9 & ITCC-7057 & Compost & New Delhi & Delhi & KF144647 & KF668129 & T. harzianum \\
\hline H-10 & ITCC-7077 & Sugarcane soil & Navasari & Gujarat & KF144648 & KF668130 & T. harzianum \\
\hline H-11 & ITCC-7368 & $\begin{array}{c}\text { Chikpearhizospher } \\
\text { e soil }\end{array}$ & New Delhi & Delhi & KF144649 & KF668131 & T. harzianum \\
\hline H-12 & ITCC-7354 & Soil & Navasari & Gujarat & KF144650 & KF668132 & T. harzianum \\
\hline H-16 & ITCC-7355 & Compost & Jammu & J\& K & KF144654 & KF668136 & T. harzianum \\
\hline H-18 & ITCC-7342 & Soil & New Delhi & Delhi & KF144656 & KF668138 & T. harzianum \\
\hline H-21 & ITCC-7357 & Soil & Shalimar & $\mathbf{J} \& \mathbf{K}$ & KF144659 & KF668141 & T. harzianum \\
\hline H-24 & ITCC-7346 & Soil & Bapatla & AndhraPradesh & KF144662 & KF668144 & T. harzianum \\
\hline H-26 & ITCC-7348 & Soil & Bapatla & AndhraPradesh & KF144664 & KF668146 & T. harzianum \\
\hline H-28 & ITCC-7350 & Soil & Bapatla & AndhraPradesh & KF144666 & KF668148 & T. harzianum \\
\hline
\end{tabular}


Table.3 Specific activity of hydrolytic enzymes produced by the Trichoderma isolates without interaction

\begin{tabular}{|c|c|c|c|c|c|}
\hline \multicolumn{6}{|c|}{ Specific activity IU mg ${ }^{-1}$} \\
\hline Isolates & Cellulase & B-1-3 glucanase & B-1-4 glucanase & Chitinase & Protease \\
\hline $\mathrm{V}-7$ & 10.46 & 11.21 & 18.85 & 19.68 & 15.19 \\
\hline $\mathrm{V}-8$ & 13.00 & 7.75 & 7.13 & 12.78 & 5.60 \\
\hline V-9 & 9.71 & 8.50 & 7.60 & 9.70 & 6.00 \\
\hline $\mathrm{V}-17$ & 14.00 & 7.93 & 9.42 & 18.01 & 6.86 \\
\hline $\mathrm{V}-19$ & 21.85 & 18.19 & 17.10 & 10.29 & 16.01 \\
\hline $\mathrm{V}-21$ & 10.02 & 18.00 & 17.04 & 14.11 & 15.27 \\
\hline $\mathrm{V}-22$ & 9.00 & 7.75 & 6.15 & 10.25 & 6.25 \\
\hline $\mathrm{V}-23$ & 9.65 & 7.30 & 6.56 & 16.56 & 5.65 \\
\hline $\mathrm{V}-4$ & 6.17 & 4.08 & 6.87 & 9.16 & 3.88 \\
\hline $\mathrm{V}-18$ & 6.80 & 5.86 & 5.05 & 9.25 & 4.26 \\
\hline SEm \pm & 0.61 & 0.31 & 0.22 & 1.29 & 0.79 \\
\hline$C D(p=0.05)$ & 3.10 & 2.23 & 1.86 & 1.42 & 3.53 \\
\hline $\mathrm{H}-2$ & 8.56 & 8.78 & 10.54 & 10.74 & 8.51 \\
\hline $\mathrm{H}-3$ & 8.83 & 9.42 & 9.84 & 13.83 & 8.12 \\
\hline $\mathrm{H}-7$ & 10.96 & 9.44 & 10.45 & 20.95 & 7.53 \\
\hline $\mathrm{H}-9$ & 13.23 & 8.20 & 9.58 & 19.66 & 9.10 \\
\hline $\mathrm{H}-10$ & 18.64 & 13.16 & 12.06 & 34.63 & 18.05 \\
\hline H-11 & 10.55 & 8.59 & 11.57 & 10.23 & 9.15 \\
\hline H-12 & 18.64 & 10.41 & 17.95 & 19.55 & 11.00 \\
\hline H-16 & 12.77 & 7.71 & 9.86 & 22.14 & 8.95 \\
\hline H-18 & 10.70 & 8.50 & 9.20 & 15.74 & 10.36 \\
\hline H-21 & 16.35 & 10.05 & 10.60 & 24.20 & 18.56 \\
\hline H-26 & 10.87 & 8.46 & 9.21 & 25.34 & 8.83 \\
\hline H-28 & 12.63 & 8.32 & 8.52 & 24.62 & 10.50 \\
\hline H-6 & 8.33 & 5.42 & 4.16 & 5.91 & 4.92 \\
\hline H-24 & 7.43 & 4.33 & 5.73 & 8.82 & 6.03 \\
\hline SEm \pm & 1.35 & 0.27 & 0.31 & 0.86 & 1.01 \\
\hline$C D(p=0.05)$ & 4.63 & 2.08 & 2.22 & 1.17 & 4.01 \\
\hline
\end{tabular}


Table.4 Specific activity of hydrolytic enzymes produced by the Trichoderma isolates during the interaction

\begin{tabular}{|c|c|c|c|c|c|c|c|c|c|c|c|c|c|c|c|}
\hline \multicolumn{16}{|c|}{ Specific activity IU mg $^{-1}$} \\
\hline \multirow{2}{*}{ Isolates } & \multicolumn{3}{|c|}{ Cellulase } & \multicolumn{3}{|c|}{ B-1,3 Glucanase } & \multicolumn{3}{|c|}{ B-1,4 Glucanase } & \multicolumn{3}{|c|}{ Chitinase } & \multicolumn{3}{|c|}{ Protease } \\
\hline & $\begin{array}{c}F . \\
\text { oxysporum }\end{array}$ & $\begin{array}{c}R . \\
\text { solani }\end{array}$ & $\begin{array}{c}\text { S. } \\
\text { rolfsii }\end{array}$ & $\begin{array}{c}F . \\
\text { oxyspoum }\end{array}$ & $\begin{array}{c}R . \\
\text { solani }\end{array}$ & $\begin{array}{c}S . \\
\text { rolfsii }\end{array}$ & $\begin{array}{c}F . \\
\text { oxysporum }\end{array}$ & $\begin{array}{c}R . \\
\text { solani }\end{array}$ & $\begin{array}{c}S . \\
\text { rolfsii }\end{array}$ & $\begin{array}{c}F . \\
\text { oxyspoum }\end{array}$ & $\begin{array}{c}R . \\
\text { solani }\end{array}$ & $\begin{array}{c}S . \\
\text { rolfsii }\end{array}$ & $\begin{array}{c}F . \\
\text { oxyspoum }\end{array}$ & $\begin{array}{c}R . \\
\text { solani }\end{array}$ & $\begin{array}{c}S . \\
\text { rolfsii }\end{array}$ \\
\hline V-7 & 34.88 & 42.11 & 10.71 & 12.21 & 16.20 & 14.70 & 18.22 & 10.46 & 16.32 & 20.56 & 33.29 & 20.31 & 18.94 & 18.29 & 18.50 \\
\hline V-8 & 10.65 & 22.84 & 15.28 & 13.45 & 8.27 & 6.31 & 14.44 & 7.29 & 10.58 & 18.56 & 13.30 & 18.14 & 8.65 & 8.23 & 6.29 \\
\hline V-9 & 15.06 & 11.71 & 12.93 & 10.48 & 9.67 & 6.92 & 9.36 & 7.53 & 8.30 & 10.27 & 14.02 & 19.60 & 7.70 & 11.10 & 8.14 \\
\hline V-17 & 9.58 & 15.69 & 15.69 & 11.89 & 9.75 & 8.92 & 13.71 & 11.89 & 14.78 & 30.13 & 38.73 & 14.98 & 12.06 & 15.87 & 12.05 \\
\hline V-19 & 22.94 & 31.40 & 30.31 & 19.56 & 12.29 & 19.01 & 19.28 & 19.28 & 16.79 & 20.31 & 22.58 & 24.21 & 19.44 & 18.17 & 17.13 \\
\hline V-21 & 26.91 & 15.17 & 16.75 & 10.02 & 10.82 & 16.46 & 17.52 & 10.68 & 19.43 & 24.33 & 18.70 & 22.71 & 17.11 & 18.48 & 18.20 \\
\hline V-22 & 9.21 & 12.72 & 10.31 & 9.71 & 8.61 & 6.31 & 8.21 & 9.21 & 8.76 & 17.24 & 13.58 & 12.24 & 8.30 & 9.06 & 6.43 \\
\hline V-23 & 13.73 & 16.62 & 11.48 & 9.97 & 10.19 & 7.83 & 9.22 & 4.83 & 9.60 & 24.37 & 14.22 & 19.56 & 7.63 & 8.37 & 6.83 \\
\hline V-4 & 8.41 & 8.83 & 7.71 & 6.03 & 4.06 & 4.06 & 7.57 & 6.73 & 9.46 & 8.57 & 12.16 & 14.99 & 2.60 & 4.19 & 3.29 \\
\hline V-18 & 7.55 & 10.38 & 8.49 & 7.41 & 7.14 & 6.20 & 7.28 & 5.93 & 7.89 & 9.89 & 11.28 & 11.81 & 6.21 & 7.44 & 4.87 \\
\hline SEm \pm & 0.86 & 0.48 & 0.48 & 0.05 & 0.05 & 0.01 & 0.21 & 0.21 & 0.12 & 0.05 & 0.04 & 0.05 & 0.01 & 0.01 & 0.01 \\
\hline $\begin{array}{c}\text { CD } \\
(p=0.05)\end{array}$ & 3.68 & 2.76 & 2.76 & 0.92 & 0.92 & 0.01 & 1.84 & 1.84 & 1.38 & 0.93 & $\mathbf{0 . 8 0}$ & 0.93 & 0.34 & 0.17 & 0.25 \\
\hline H-2 & 11.42 & 16.91 & 15.15 & 12.96 & 8.78 & 9.66 & 12.74 & 12.08 & 13.72 & 17.00 & 51.72 & 18.57 & 16.32 & 8.77 & 9.61 \\
\hline H-3 & 10.86 & 24.27 & 26.31 & 10.18 & 12.39 & 12.90 & 11.54 & 9.50 & 14.85 & 49.29 & 23.37 & 31.99 & 12.49 & 7.47 & 12.32 \\
\hline H-7 & 18.88 & 28.82 & 13.99 & 12.81 & 10.62 & 11.63 & 12.14 & 13.32 & 13.74 & 22.33 & 23.21 & 22.84 & 8.83 & 8.08 & 8.10 \\
\hline H-9 & 13.23 & 24.12 & 15.85 & 10.06 & 9.78 & 11.44 & 13.23 & 8.82 & 12.75 & 26.12 & 28.24 & 23.73 & 10.04 & 13.42 & 11.25 \\
\hline H-10 & 17.54 & 19.19 & 18.09 & 10.41 & 15.90 & 16.44 & 10.41 & 13.16 & 17.81 & 83.78 & 62.63 & 88.80 & 13.44 & 31.37 & 23.88 \\
\hline H-11 & 13.27 & 14.12 & 13.44 & 9.53 & 9.02 & 13.10 & 12.25 & 9.19 & 16.25 & 17.51 & 21.34 & 15.43 & 9.67 & 17.01 & 10.35 \\
\hline H-12 & 20.83 & 52.07 & 23.57 & 10.96 & 16.44 & 18.09 & 15.35 & 13.70 & 19.59 & 39.65 & 23.54 & 43.56 & 13.14 & 21.90 & 23.88 \\
\hline H-16 & 13.33 & 14.30 & 14.30 & 9.30 & 8.47 & 9.58 & 9.02 & 11.94 & 12.29 & 27.02 & 24.92 & 27.30 & 10.89 & 14.24 & 16.06 \\
\hline H-18 & 17.60 & 15.10 & 22.90 & 13.90 & 9.50 & 14.90 & 8.80 & 9.20 & 9.75 & 16.91 & 19.58 & 18.03 & 13.19 & 14.03 & 15.10 \\
\hline H-21 & 15.02 & 18.33 & 29.22 & 13.03 & 13.92 & 18.78 & 12.37 & 11.93 & 22.42 & 43.89 & 25.46 & 29.26 & 14.20 & 10.26 & 14.63 \\
\hline H-26 & 12.48 & 17.62 & 23.06 & 10.77 & 9.06 & 17.82 & 10.67 & 9.77 & 15.25 & 29.34 & 31.92 & 25.95 & 12.95 & 10.31 & 16.17 \\
\hline H-28 & 13.24 & 14.74 & 20.36 & 9.63 & 10.33 & 9.33 & 13.34 & 9.53 & 9.98 & 28.81 & 29.95 & 29.53 & 13.60 & 15.26 & 14.23 \\
\hline H-6 & 7.99 & 9.39 & 8.74 & 7.91 & 6.50 & 6.17 & 6.42 & 7.71 & 8.62 & 10.84 & 18.87 & 12.74 & 9.84 & 4.84 & 7.78 \\
\hline H-24 & 9.15 & 5.23 & 7.44 & 9.25 & 8.39 & 8.67 & 8.20 & 7.01 & 8.31 & 15.37 & 16.93 & 14.99 & 8.17 & 6.27 & 9.45 \\
\hline SEm \pm & 2.14 & 5.02 & 1.19 & 0.12 & 0.13 & 0.01 & 0.53 & 0.52 & 0.30 & 0.13 & 0.10 & 0.13 & 0.01 & 0.01 & 0.01 \\
\hline $\begin{array}{c}\text { CD } \\
(p=0.05)\end{array}$ & 5.84 & 0.89 & 4.35 & 1.43 & 1.44 & 1.01 & 2.90 & 2.88 & 2.19 & 1.46 & 1.26 & 1.42 & 0.54 & 0.26 & 0.40 \\
\hline
\end{tabular}


Table.5 Grouping of Trichoderma virens and Trichoderma harzianum isolates based on specific enzymatic activity without and during interaction with soil-borne pathogens

\begin{tabular}{|c|c|c|c|c|c|c|c|c|}
\hline Interaction & $\begin{array}{c}\text { Specific } \\
\text { activity of } \\
\text { enzymes }\end{array}$ & Groups & $\begin{array}{c}\text { Name of } \\
\text { the species }\end{array}$ & Cellulase & B-1,3 Glucanase & $\begin{array}{c}\text { B-1,4 } \\
\text { Glucanase }\end{array}$ & Chitinase & Protease \\
\hline \multirow{6}{*}{$\begin{array}{c}\text { Trichoderma } \\
\text { without interaction }\end{array}$} & \multirow[b]{2}{*}{ High } & \multirow{2}{*}{$\begin{array}{l}\text { Group-1 } \\
\text { (>20 } \\
\text { IU/mg) } \\
\text { Specific } \\
\text { activity }\end{array}$} & T. virens & V-19 & None & None & None & None \\
\hline & & & $\begin{array}{c}T . \\
\text { harzianum }\end{array}$ & None & None & None & $\begin{array}{c}\mathrm{H}-7, \mathrm{H}-10, \mathrm{H}-16, \mathrm{H}-21, \mathrm{H}- \\
26, \mathrm{H}-28\end{array}$ & None \\
\hline & \multirow[b]{2}{*}{ Moderate } & \multirow{2}{*}{$\begin{array}{l}\text { Group-2 } \\
(10-20 \\
\text { IU/mg) } \\
\text { Specific } \\
\text { activity }\end{array}$} & T. virens & $\begin{array}{l}\text { V-7, V-8, V- } \\
\text { 17, V-21 }\end{array}$ & V-7, V-19, V-21 & $\begin{array}{c}\text { V-7, V-19, V- } \\
21\end{array}$ & $\begin{array}{c}\text { V-7, V-8, V-17, } \\
\text { V-19, V-21, V-22, V-23 }\end{array}$ & V-7, V-19, V-21 \\
\hline & & & $\begin{array}{c}T . \\
\text { harzianum }\end{array}$ & $\begin{array}{c}\text { H-7, H-9, H- } \\
10, \text { H-11, H- } \\
\text { 12, H-16, H- } \\
\text { 18, H-21, H- } \\
\text { 26, H-28 }\end{array}$ & H-10, H-12, H-21 & $\begin{array}{c}\text { H-2, H-7, H-10, } \\
\text { H-11, H-12, H- } \\
21\end{array}$ & $\begin{array}{c}\text { H-2, H-3, H-9, } \\
\text { H-11, H-12, H-18, }\end{array}$ & $\begin{array}{c}\text { H-10, H-12, H-18, H-21, } \\
\text { H-28 }\end{array}$ \\
\hline & \multirow[b]{2}{*}{ Low } & \multirow{2}{*}{$\begin{array}{l}\text { Group-3 } \\
\text { (0-10 } \\
\text { IU/mg) } \\
\text { Specific } \\
\text { activity }\end{array}$} & T. virens & $\begin{array}{l}\text { V-4, V-9, V-18, } \\
\text { V-22, V-23 }\end{array}$ & $\begin{array}{c}\mathrm{V}-4, \mathrm{~V}-8, \mathrm{~V}-9, \mathrm{~V}-17, \mathrm{~V}- \\
18, \mathrm{~V}-22, \mathrm{~V}-23\end{array}$ & $\begin{array}{c}\text { V-4, V-8, V-9, } \\
\text { V-17, V-18, V- } \\
22, \text { V-23 }\end{array}$ & V-4, V-9, V-18 & $\begin{array}{c}\text { V-4, V-8, V-9, } \\
\text { V-17, V-18, V-22, V-23 }\end{array}$ \\
\hline & & & $\begin{array}{c}T . \\
\text { harzianum }\end{array}$ & $\begin{array}{c}\text { H-2, H-3, H-6, } \\
\text { H-24 }\end{array}$ & $\begin{array}{c}\text { H-2, H-3, H-6, H-7, H-9, } \\
\text { H-11, H-16, } \\
\text { H-18, H-24, H-26, H-28 }\end{array}$ & $\begin{array}{l}\text { H-3, H-6, H-9, } \\
\text { H-16, H-18, H- } \\
24, \text { H-26, H-28 }\end{array}$ & H-6, H-24 & $\begin{array}{l}\text { H-2, H-3, H-6, H-7, H-9, } \\
\text { H-11, H-16, H-24, H-26 }\end{array}$ \\
\hline \multirow{6}{*}{$\begin{array}{l}\text { Trichoderma } \\
\text { species with } \\
\text { Fusarium } \\
\text { oxysporum }\end{array}$} & \multirow{2}{*}{ High } & \multirow{2}{*}{$\begin{array}{l}\text { Group-1 } \\
\text { (>20 } \\
\text { IU/mg) } \\
\text { Specific } \\
\text { activity }\end{array}$} & T. virens & $\begin{array}{l}\mathrm{V}-7, \mathrm{~V}-19, \mathrm{~V}- \\
21\end{array}$ & None & None & $\begin{array}{c}\text { V-7, V-17, V-19, } \\
\text { V-21, V-23 }\end{array}$ & None \\
\hline & & & $\begin{array}{c}T . \\
\text { harzianum }\end{array}$ & H-12 & None & None & $\begin{array}{c}\text { H-3, H-7, H-9, H-10, H-12, } \\
\text { H-16, H-21, H-26, H-28 }\end{array}$ & None \\
\hline & \multirow[b]{2}{*}{ Moderate } & \multirow{2}{*}{$\begin{array}{l}\text { Group-2 } \\
(10-20 \\
\text { IU/mg) } \\
\text { Specific } \\
\text { activity }\end{array}$} & T. virens & V-8, V-9, V-23 & $\begin{array}{c}\mathrm{V}-7, \mathrm{~V}-8, \mathrm{~V}-9, \mathrm{~V}-17, \mathrm{~V}- \\
19, \mathrm{~V}-21\end{array}$ & $\begin{array}{l}\text { V-7, V-8, V-17, } \\
\text { V-19, V-21 }\end{array}$ & V-8, V-9, V-22 & $\begin{array}{c}\text { V-7, V-17, V-19, } \\
\text { V-21 }\end{array}$ \\
\hline & & & $\begin{array}{c}T . \\
\text { harzianum }\end{array}$ & $\begin{array}{c}\text { H-2, H-3, H-7, } \\
\text { H-9, H-10, H- } \\
11, \text { H-16, H- } \\
18, \text { H-21, H- } \\
26, \text { H-28 }\end{array}$ & $\begin{array}{c}\text { H-2, H-3, H-7, H-9, H-10, } \\
\text { H-12, H-18, H-21, H-26 }\end{array}$ & $\begin{array}{c}\text { H-2, H-3, H-7, } \\
\text { H-9, H-10, H- } \\
\text { 11, H-12, H-21, } \\
\text { H-26, H-28 }\end{array}$ & $\begin{array}{c}\text { H-2, H-6, H-11, } \\
\text { H-18, H-24 }\end{array}$ & $\begin{array}{c}\text { H-2, H-3, H-9, H-10, H- } \\
\text { 12, H-16, H-18, H-21, } \\
\text { H-26, H-28 }\end{array}$ \\
\hline & \multirow{2}{*}{ Low } & \multirow{2}{*}{$\begin{array}{l}\text { Group-3 } \\
\text { (0-10 } \\
\text { IU/mg) } \\
\text { Specific } \\
\text { activity }\end{array}$} & T. virens & $\begin{array}{c}\mathrm{V}-4, \mathrm{~V}-17, \mathrm{~V}- \\
18, \\
\mathrm{~V}-22\end{array}$ & $\begin{array}{l}\text { V-4, V-18, } \\
\text { V-22, V-23 }\end{array}$ & $\begin{array}{c}\text { V-4, V-9, V-18, } \\
\text { V-22, V-23 }\end{array}$ & $V-4, V-18$ & $\begin{array}{c}\mathrm{V}-4, \mathrm{~V}-8, \mathrm{~V}-9, \\
\mathrm{~V}-18, \mathrm{~V}-22, \mathrm{~V}-23\end{array}$ \\
\hline & & & $\begin{array}{c}\text { T. } \\
\text { harzianum }\end{array}$ & H-6, H-24 & $\begin{array}{l}\text { H-6, H-11, H-16, } \\
\text { H-24, H-28 }\end{array}$ & $\begin{array}{c}\text { H-6, H-16, H- } \\
18, \\
\text { H-24 }\end{array}$ & None & $\begin{array}{c}\text { H-6, } \mathrm{H-7,} \text { H-11, } \\
\text { H-24 }\end{array}$ \\
\hline
\end{tabular}




\begin{tabular}{|c|c|c|c|c|c|c|c|c|}
\hline \multirow{6}{*}{$\begin{array}{c}\text { Trichoderma } \\
\text { species with } \\
\text { Rhizoctonia solani }\end{array}$} & \multirow[b]{2}{*}{ High } & \multirow{2}{*}{$\begin{array}{l}\text { Group-1 } \\
\quad(>20 \\
\text { IU/mg) } \\
\text { Specific } \\
\text { activity }\end{array}$} & T. virens & V-7, V-8, V-19 & None & None & V-7, V-17, V-19 & None \\
\hline & & & $\begin{array}{c}T . \\
\text { harzianum }\end{array}$ & $\begin{array}{c}\text { H-3, H-7, H-9, } \\
\text { H-12 }\end{array}$ & None & None & $\begin{array}{c}\text { H-2, H-3, H-7, H-9, H-10, } \\
\text { H-11, H-12, H-16, H-21, } \\
\text { H-26, H-28 }\end{array}$ & H-10, H-12 \\
\hline & \multirow[b]{2}{*}{ Moderate } & \multirow{2}{*}{$\begin{array}{c}\text { Group-2 } \\
\text { (10-20 } \\
\text { IU/mg) } \\
\text { Specific } \\
\text { activity }\end{array}$} & T. virens & $\begin{array}{l}\text { V-9, V-17, V- } \\
18, \\
\text { V-21, V-22, V- } \\
23\end{array}$ & $\begin{array}{c}\mathrm{V}-7, \mathrm{~V}-19, \mathrm{~V}-21, \\
\mathrm{~V}-23\end{array}$ & $\begin{array}{c}\text { V-7, V-17, V- } \\
19 \\
\text { V-21 }\end{array}$ & $\begin{array}{c}\text { V-4, V-8, V-9, V-18, V-21, } \\
\text { V-22, V-23 }\end{array}$ & $\begin{array}{c}\text { V-7, V-9, V-17, } \\
\text { V-19, V-21 }\end{array}$ \\
\hline & & & $\begin{array}{c}T . \\
\text { harzianum }\end{array}$ & $\begin{array}{c}\text { H-2, } \mathrm{H}-10, \mathrm{H}- \\
11, \\
\text { H-16, H-18, H- } \\
21, \\
\text { H-26, H-28 } \\
\end{array}$ & $\begin{array}{l}\text { H-3, H-7, H-10, } \\
\text { H-12, H-21, H-28 }\end{array}$ & $\begin{array}{c}\text { H-2, H-7, H-10, } \\
\text { H-12, H-16, H- } \\
21\end{array}$ & H-6, H-18, H-24 & $\begin{array}{c}\text { H-9, H-11, H-16, } \\
\text { H-18, H-21, H-26, } \\
\text { H-28 }\end{array}$ \\
\hline & \multirow{2}{*}{ Low } & \multirow{2}{*}{$\begin{array}{c}\text { Group-3 } \\
(0-10 \\
\text { IU/mg) } \\
\text { Specific } \\
\text { activity }\end{array}$} & T. virens & $V-4$ & $\begin{array}{c}\mathrm{V}-4, \mathrm{~V}-8, \mathrm{~V}-9, \mathrm{~V}-17, \mathrm{~V}- \\
18, \mathrm{~V}-22\end{array}$ & $\begin{array}{c}\text { V-4, V-8, V-9, } \\
\text { V-18, V-22, V- } \\
23\end{array}$ & None & $\begin{array}{c}\text { V-4, V-8, V-18, } \\
\text { V-22, V-23 }\end{array}$ \\
\hline & & & $\begin{array}{c}T . \\
\text { harzianum }\end{array}$ & H-6, H-24 & $\begin{array}{c}\text { H-2, H-6, H-9, H-11, } \\
\text { H-16, H-18, H-24, H-26, }\end{array}$ & $\begin{array}{l}\text { H-3, H-6, H-9, } \\
\text { H-11, H-18, H- } \\
24, \text { H-26, H-28 }\end{array}$ & None & $\begin{array}{c}\mathrm{H}-2, \mathrm{H}-3, \mathrm{H}-6, \mathrm{H}-7, \\
\text { H-24 }\end{array}$ \\
\hline \multirow{6}{*}{$\begin{array}{c}\text { Trichoderma } \\
\text { species with } \\
\text { Sclerotiumrolsfii }\end{array}$} & \multirow[b]{2}{*}{ High } & \multirow{2}{*}{$\begin{array}{c}\text { Group-1 } \\
\text { (>20 } \\
\text { IU/mg) } \\
\text { Specific } \\
\text { activity }\end{array}$} & T. virens & V-19 & None & None & $V-7, V-19, V-21$ & None \\
\hline & & & $\begin{array}{c}T . \\
\text { harzianum }\end{array}$ & $\begin{array}{c}\text { H-3, H-12, H- } \\
18, \\
\text { H-21, H-26, } \\
\text { H-28 } \\
\end{array}$ & None & H-21 & $\begin{array}{c}\text { H-3, H-7, H-9, H-10, H-12, } \\
\text { H-16, H-21, H-26, H-28 }\end{array}$ & H-10, H-12 \\
\hline & \multirow[b]{2}{*}{ Moderate } & \multirow{2}{*}{$\begin{array}{c}\text { Group-2 } \\
\text { (10-20 } \\
\text { IU/mg) } \\
\text { Specific } \\
\text { activity }\end{array}$} & T. virens & $\begin{array}{c}\text { V-7, V-8, V-9, } \\
\text { V-17, V-21, V- } \\
22, \text { V-23 }\end{array}$ & V-7, V-19, V-21 & $\begin{array}{c}\text { V-7, V-8, V- } \\
17, \\
\text { V-19, V-21 }\end{array}$ & $\begin{array}{c}\text { V-4, V-8, V-9, } \\
\text { V-17, V-18, V-22, V-23 }\end{array}$ & $\begin{array}{c}\mathrm{V}-7, \mathrm{~V}-17, \mathrm{~V}-19, \\
\mathrm{~V}-21\end{array}$ \\
\hline & & & $\begin{array}{c}T . \\
\text { harzianum }\end{array}$ & $\begin{array}{c}\text { H-2, H-7, H-9, } \\
\text { H-10, H-11, H- } \\
16\end{array}$ & $\begin{array}{c}\text { H-3, H-7, H-9, H-10, H- } \\
\text { 11, H-12, H-18, H-21, } \\
\text { H-26 }\end{array}$ & $\begin{array}{c}\text { H-2, H-3, H-7, } \\
\text { H-9, H-10, H- } \\
\text { 11, H-12, H- } \\
\text { 16, H-26 }\end{array}$ & $\begin{array}{l}\text { H-2, H-6, H-11, } \\
\text { H-18, H-24 }\end{array}$ & $\begin{array}{c}\text { H-3, H-9, H-11, } \\
\text { H-16, H-18, H-21, H- } \\
26, \text { H-28 }\end{array}$ \\
\hline & \multirow[t]{2}{*}{ Low } & \multirow{2}{*}{$\begin{array}{l}\text { Group-3 } \\
(\mathbf{0 - 1 0} \\
\text { IU/mg) } \\
\text { Specific } \\
\text { activity }\end{array}$} & T. virens & V-4, V-18 & $\begin{array}{c}\mathrm{V}-4, \mathrm{~V}-8, \mathrm{~V}-9, \mathrm{~V}-17, \mathrm{~V}- \\
18, \mathrm{~V}-22, \mathrm{~V}-23\end{array}$ & $\begin{array}{c}\mathrm{V}-4, \mathrm{~V}-9, \mathrm{~V}- \\
18, \\
\mathrm{~V}-22, \mathrm{~V}-23\end{array}$ & None & $\begin{array}{c}\text { V-4, V-8, V-9, } \\
\text { V-18, V-22, V-23 }\end{array}$ \\
\hline & & & $\begin{array}{c}T . \\
\text { harzianum }\end{array}$ & H-6, H-24 & $\begin{array}{c}\text { H-2, H-6, H-16, } \\
\text { H-24, H-28 }\end{array}$ & $\begin{array}{c}\text { H-6, H-18, H- } \\
24, \text { H-28 }\end{array}$ & None & $\begin{array}{l}\text { H-2, H-6, H-7, } \\
\text { H-24 }\end{array}$ \\
\hline
\end{tabular}


Table.6 High and low potential isolates of T. virens and T. harzianum selected on the basis of enzyme activity studies

\begin{tabular}{ccc}
\hline Name of the species & High potential & Low potential \\
\hline Trichoderma virens & $\mathrm{V}-7, \mathrm{~V}-19, \mathrm{~V}-21$ & $\mathrm{~V}-4$ \\
& $(03$ isolates $)$ & $(01$ isolates $)$ \\
Trichodermaharzianum & $\mathrm{H}-10, \mathrm{H}-12, \mathrm{H}-21$ & $\mathrm{H}-6$ \\
& $(03$ isolates $)$ & $(01$ isolate $)$ \\
\hline
\end{tabular}

Fig.1 A representative gel picture showing amplification profile of twenty four isolates of $T$. virens $(\mathrm{V})$ and $T$. harzianum $(\mathrm{H})$ using ITS $1 \& 4$ region nucleotide sequence (Table 1 ) for molecular conformation of isolates

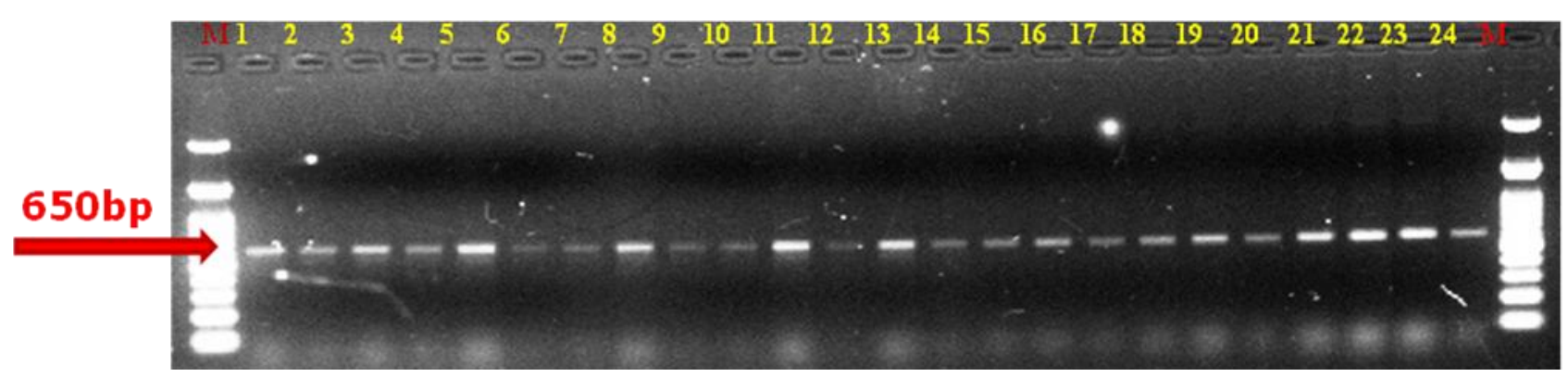

M: $1 \mathrm{~Kb}$ DNA Ladder (both the side),Lane 1-24 isolates: V-4, V-7, V-8, V-9, V-17, V-18, V-19, V-21, V-22, V-23, H-2, H-3,H-6, H-7, H-9, H-10, H-11, H-12, H-16, H-18, H-21, H-24, H-26 and H-28.

Fig.2 A representative gel picture showing amplification profile of twenty four isolates of $T$. virens $(\mathrm{V})$ and $T$. harzianum $(\mathrm{H})$ using tef-1 region nucleotide sequence (Table 1) for molecular conformation of isolates

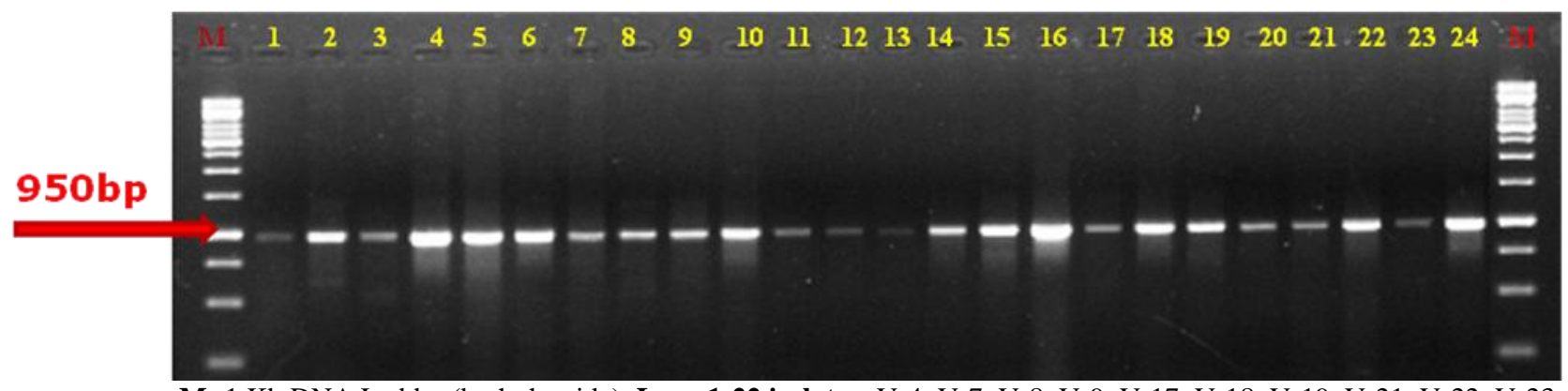

M: $1 \mathrm{~Kb}$ DNA Ladder (both the side), Lane 1-22 isolates: V-4, V-7, V-8, V-9, V-17, V-18, V-19, V-21, V-22, V-23, H-2, H-3, H-6, H-7, H-9, H-10, H-11, H-12, H-16, H-18, H-21, H-24, H-26 and H-28. 
Fig.3 Phylogenetic relationship of twenty four isolates of Trichoderma species based on ITS $1 \&$ 4 region of nucleotide sequence aligned using software MEGA $5.2 \mathrm{v}$. the tree was generated by the Maximum parsimony analysis method

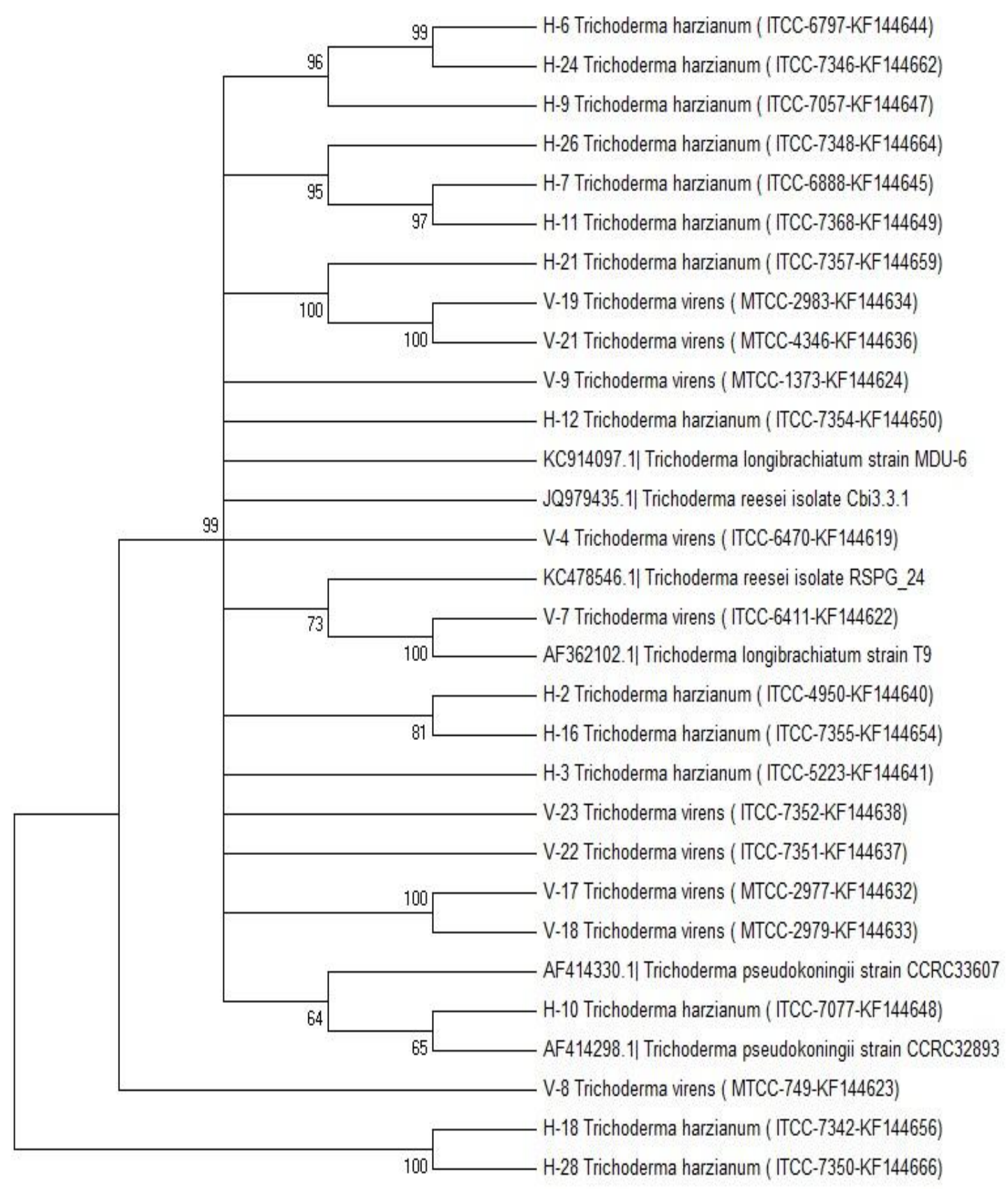


Fig.4 Phylogenetic relationship of twenty four isolates of Trichoderma species based on tef-1 region of nucleotide sequence aligned using software MEGA 5.2 v. The tree was generated by the Maximum parsimony analysis method

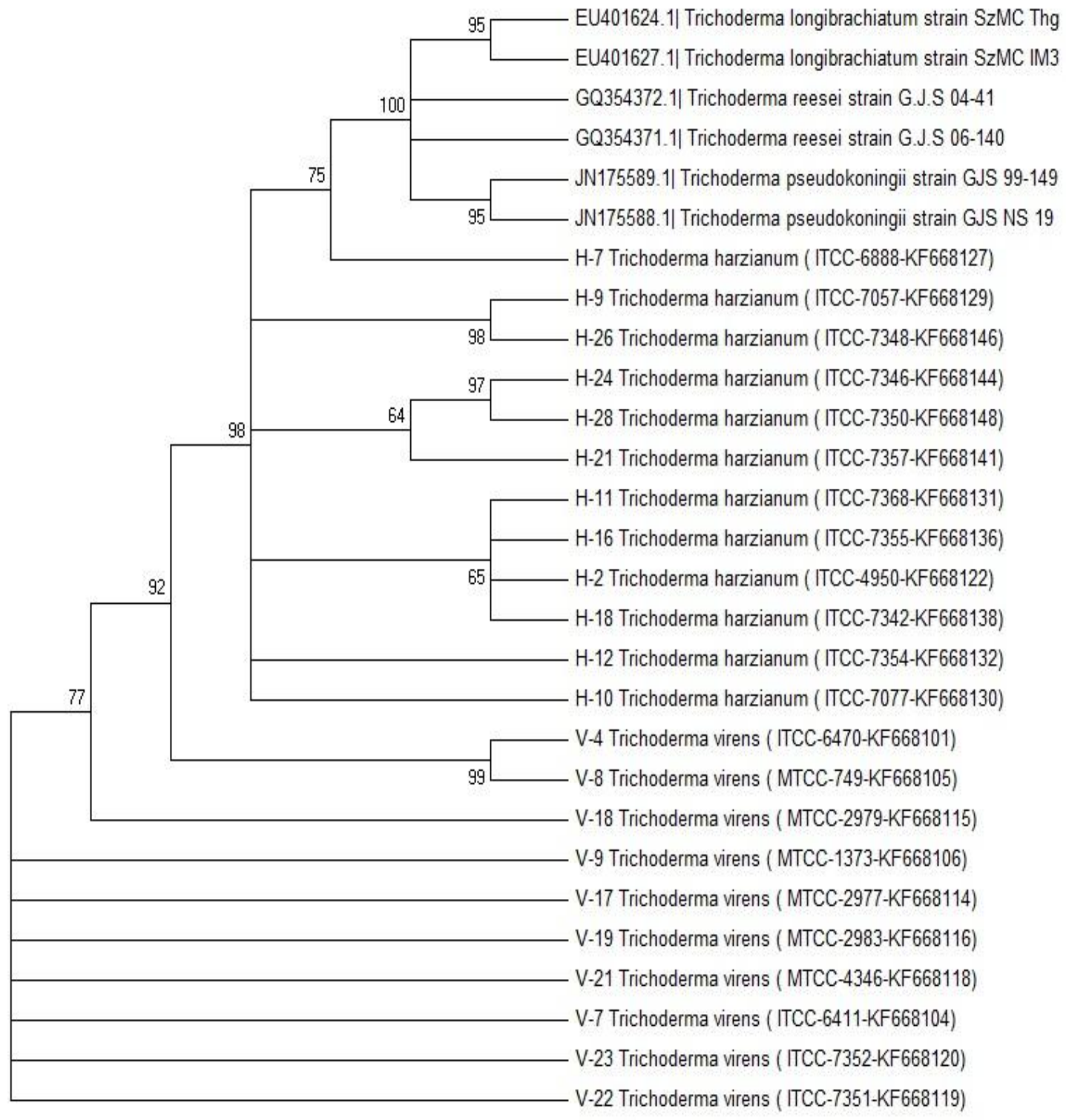

The highest hydrolytic enzymes production viz., cellulase, $\beta-1, \quad 3$-glucanase, $\beta-1, \quad 4-$ glucanase, chitinase and protease were observed in $T$. harzianum in both without and also during antagonism studies comparable with $T$. virens isolates. Further, it was also found that cultivation of Trichoderma isolates with soil borne pathogen (during interaction) produce high hydrolytic enzymes compared to cultivation of Trichoderma species alone. The enzymatic production were categorized into $>20 \mathrm{IU} / \mathrm{mg}$ as high, $10-20 \mathrm{IU} / \mathrm{mg}$ as moderate and 0-10 IU/mg as low potential.

A total of 10 isolates of T.virens were tested, only three isolates viz., V-7, V-19 and V-21 were considered as high potential isolates and the isolate $\mathrm{V}$-4considered as a low potential based on the specific activity of the enzymes. Similarly, a total of14 isolates of 
T. harzianum were tested, only three isolates such as $\mathrm{H}-10, \mathrm{H}-12$ and $\mathrm{H}-21$ were considered as high potential and the isolate $\mathrm{H}-6$ was considered as low potential based on the specific activity of the enzymes. There are many reports demonstrating that cellulase, $\beta$ 1,3glucanase, $\beta$-1,4glucanase, chitinase and proteases are effective features associated with the ability of Trichoderma to control plant pathogens (Brimner et al., 2003; Haran et al., 1996; Wang et al., 2003; Lorito et al., 1994).

In conclusion, present investigation was carryout to investigate molecular taxonomy (based on ITS $1 \& 4$ and tef- 1 sequences analysis) and biochemical characterization (based on hydrolytic enzymes such as cellulase, $\beta$-13, 3-glucanase, $\beta$-1, 4-glucanase, chitinase and protease) of selected (through bio-efficacy tests) isolates of Trichoderma which intern helps in understanding the mechanism of biological control activity. The twenty four isolates of Trichoderma were molecularly analyzed for the confirmation of its species with their morphology using ITS 1 $\& 4$ and tef- 1 regions. tef- 1 region was found better to separate the $T$. virens and $T$. harzianum in the present study. Three isolates of $T$. virensviz., $\mathrm{V}-7, \mathrm{~V}-19$ and $\mathrm{V}-21$ and another three isolates of $T$. harzinaum such as $\mathrm{H}-10,12$ and $\mathrm{H}-21$ were selected as potential based on their high specific enzymatic activity (>20 IU/mg) and identified isolates could be used as bio-control agents against $F$. oxysporum, R. solani and S.rolsfii.

Acknowledgements: The authors are thankful to the ICAR-Indian Agriculture Research Institute for providing the facilities to carry out this study and UGC for financial support.

\section{References}

Baek, J.M., Howell, C.R. and Kenerley, C.M. 1999. The role of an extracellular chitinase from Trichoderma virens Gv298 in the bio-control of Rhizoctonia solani. Curr. Genetics, 35: 41-50.

Bradford, M.M. 1976. Rapid and sensitive method for the quantization of microgram quantities of protein utilizing the principle of protein-dye binding", Annals Biochem., 72: 248-254.

Brimner, T.A. and Boland, G.J. 2003. A review of the non-target effects of fungi used to biologically control plant diseases. Agriculture, Ecosystems and Environ., 100: 3-16.

Carsolio, C., Benhamou, N., Haran, S., Cortes, C., Gutierrez, A., Chet, I. and HerreraEstrella, A. 1999. Role of the Trichodermaharzianum, endo-chitinase, ech42, in mycoparasitism. Appl. Environ. Microbiol., 65: 929-935.

Chaverri, P., Samuels, G.J. and Stewart, E.L. 2001. Hypocreavirens, the teleomorph of Trichoderma virens. Mycologia, 93: 1113-1124.

Chernin, L. and Chet, I. 2002. Microbial enzymes in biocontrol of plant pathogens and pests, pp. 171-225.

Druzhinina, I.S., Kopchinskiy, A.G., Komon, M., Bissett, J., Szakacs, G. and Kubicek, C.P. 2005. An oligonucleotide barcode for species identification in Trichoderma and Hypocrea. Fungal Genetics and Biol., 42: 813-28.

El-Katatny, M.H., Gudelj, M., Robra, K.H., Elnaghy, M.A. and Gübitz, G.M. 2001. Characterization of a chitinase and an endo-ß-1,3-glucanase from T. harzianum Rifai T-24 involved in control of the phytopathogen Sclerotiumrolfsii. Appl. Microbiol. Biotechnol., 56: 137-143.

El-Katatny, M.H., Somitsch, W., Robra, K.H., El-Katatny, M.S. and Gubitz, G.M. 2000. Production of chitinase and B1,3glucanase by Trichodermaharzianum for control of the phytopathogenic fungus Sclerotiumrolfsii. Food Technol. Biotechnol., 38: 173-180.

El-Katatny, M.S., El-Komy, H.M., Shaban, G.M., Hetta, A.M.A. and El-Katatny, M.H. 2004. Effect of benomyl on 
chitinase and $\beta-1,3$ glucanase production by free and alginate encapsulated Trichodermaharzianum. Food Technol. Biotechnol., 42: 83-88.

Geiser, D.M., Darner. J.W., Horn, B.W. and Taylor, J.W. 2004. The phylogenetics of mycotoxin and sclerotium production in Aspergillusflavusand Aspergillusoryzae. Fungal Genetics Biol., 31: 169-179.

Haran, S., Schinckler, H. and Cheet, I. 1996. Molecular Mechanism of lytic enzymes involved in the biological activity of Trichodermaharzianum. Microbiol., 142: 2312- 2331.

Harman, G.E. and Kubicek, C.P. 1998. Trichoderma and Gliocladium. Taylor \& Francis, London, pp 278.

Harman, G.E., Howell, C.R., Viterbo, A., Chet, I. and Lorito, M. 2004. Trichoderma species Opportunistic, a virulent plant symbionts. Nature Rev. Microbiol., 2: 4356.

Hermosa, M.R., Keck, E., Chamorro, I., Rubio, B., Sanz, L., Vizcaino, J.A. and Grondona, I., Monte, E. 2004. Genetic diversity shown in Trichoderma biocontrol isolates. Mycol. Res., 108: 897906.

Kimura, M.A. 1980. Simple method for estimating evolutionary rates of base substitutions through comparative studies of nucleotide sequences. Journal of Molecular Evolution.,16: 111-120.

Kubicek, C.P., Mach, R.L., Peterbauer, C.K. and Lorito, M. 2001. Trichoderma: from genes to bio-control. J. Plant Pathol., 83: 11-23.

Kulling, C., Mach, R.L., Lorito, M. and Kubicek, C.P. 2000. Enzyme diffusion from Trichodermaatroviride(T. harzianum $\mathrm{P} 1)$ to Rhizoctonia solaniis a prerequisite for triggering of Trichoderma ech42 gene expression before mycoparasitic contact. Appl. Environ. Microbiol., 66: 2232-2234.

Kullnig-Gradinger, C.M., Szakacs, G. and Kubicek, C.P. 2002. Phylogeny and evolution of the genus Trichoderma: A multigene approach. Mycol. Res., 106: 757-767.

Lorito, M. and Woo, S.L. 1998. Advances in understanding the antifungal mechanisms of Trichoderma and new applications for biocontrol. In Molecular approaches in biocontrol. Vol.21, eds, B. Duffy, U. Rosenberger, and G. defago, IOBC wrps Bulletin/ Bulletin OILB Srop, Dijon, France, pp.73-80.

Lorito, M., D’Ambrosio, M.D., Woo, S.L., Kubicek, C.P., Harman, G.E., Hayes, C.K. and Scala, F. 1996. Synergistic interaction between cell wall degrading enzymes and membrane affecting compounds. Mol. Plant Microbe Interaction, 9: 206-213.

Lorito, M., Harman, G.E., Hayes, C.K., Broadway, R.M., Tronsmo, A., Woo, S.L. and Di-Pietro, A. 1993. Chitinolytic enzymes produced by Trichodermaharzianum: Antifungal activity of purified endochitinase and chitobiosidase. Phytopathol., 83: 302307.

Lorito, M., Hayes, C.K., Di Pietro, A., Woo, S.L. and Harman, G.E. 1994. Purification, characterization and synergistic activity of a glucan 1, 3-ß- glucosidase and an Nacetyl- $\beta$-D-glucosaminidase from Trichoderma harzianum. Phytopathol., 84: 398-405.

Lorito, M., Woo, S.L., Scala, F. and Ruocco, M. 2006. The molecular biology of the interactions between Trichoderma spp., phytopathogenic fungi, and plants. Phytopathol., 96: 181-185.

Mach, R.L., Peterbauer, C.K., Payer, K., Jaksits, S., Woo, S.L., Zeilinger, S., Kullnig, C.M., Lorito, M. and Kubicek C.P. 1999. Expression of two major chitinase genes of Trichodermaatroviride (T. harzianum P1) is triggered by different regulatory signals. Appl. Environ. Microbiol., 65: 1858-63.

Miller, G.L. 1959. Use of dinitro-salicyclic acid reagent for the determination of reducing sugars. Anal. Chem., 31: 426. 
Nelson Norton. 1944. A photometric adaptation of the somogyi method for the determination of glucose. J. Biol. Chem., 153: 375-380.

Sahai, A.S. and Manocha, M.S. 1993 Chitinases of fungi and plants: their involvement in morphogenesis and host-parasite interaction. FEMS Microbiol. Rev., 11: 317-338.

Samuels, G.J. 2006. Trichoderma: Systematics, the sexual state, and ecology. Phytopathol., 96: 195-206.

Tamura, K., Peterson, D., Peterson, N., Stecher, G., Nei, M. and Kumar, S. 2011. MEGA5: Molecular Evolutionary Genetics Analysis using Maximum Likelihood, Evolutionary Distance, and Maximum Parsimony Methods. Mol. Biol. Evol., 28: 2731-2739.

Thrane, C., Jensen, D.F. and Tromo, A. 2000. Substrate colonization, strain competition, enzyme production in vitro, and biocontrol of Pythiumultimumby Trichoderma spp. isolate $\mathrm{P} 1$ and $\mathrm{T} 3$. European J. Plant Pathol., 106: 215-225.

Vinale, F., Sivasithamparam, K., Ghisalberti, E.L., Marra, R., Woo, S.L. and Lorito, M. 2008. Trichoderma-plant - pathogen interactions. Soil Biology and Biochemistry 40:1-10 and Vinale F, Sivasithamparam K, Ghisalberti EL, Marra R, Barbetti MJ, Li H. 2008. A novel role for Trichodermasecondary metabolites in the interactions with plants. Physiol. Mol. Plant Pathol., 72: 80-86.

Viterbo, A., Ramot, O., Chernin, L. and Chet, I. 2002. Significance of lytic enzymes from Trichodermaspp. in the biocontrol of fungal plant pathogens. Anton Leeuw. Int. J. G., 81: 549556.

Wang, W., Hall, A.E., O 'Malley, R. and Bleecker, A.B. 2003. Canonical histidine kinase activity of the transmitter domain of the ETR1 ethylene receptor from Arabidopsis is not required for signal transmission. Proceedings of Natatural Academy of Sciences. USA, 100: 352357.

White, T.J., Bruns, T., Lee, S. and Taylor, J. 1990. Amplification and direct sequencing of fungal ribosomal RNA genes for phylogenetics. In: Innis MA, Gelfand DH, Sninsky JJ, Thomas J, editors. PCR protocols: a guide to methods and applications. San Diego: Academic Press; pp 315.

Woo, S.L.B., Donzelli, F., Scala, R.L., Mach, G.E., Harman, C.P., Kubicek, G., Del, Sorbo and Lorito, M. 1999. Disruption of the ech42 (endochitinase-encoding) gene affects biocontrol activity in Trichodermaharzianum. Plant Mol. Plant-Microbe Interaction, 12: 419-429.

Yang, Z. and Hung, P.A. 1994. Maximum likelihood phylogenetic estimation from Program performance and availability: The codon- DNA sequences with variable rates over sites: approximate meth- based models developed in this paper involve intensive codons. J. Mol. Evol., 39: 306314.

Zeilinger, S., Galhaup, C., Payer, K., Woo, S.L., Feket, C., Lorito, M. and Kubicek, C.P. 1999. Chitinase gene expression during mycoparasitic interaction of Trichodermaharzianum with its host, Fungal Genetics and Biol., 26: 131-140.

\section{How to cite this article:}

Srinivasa, N., Deeba Kamil, Chandu Singh, Avinash Singode and Deeksha Gupta. 2017. Molecular and Biochemical Characterization of Potential Isolates of Trichoderma Species Effective against Soil-Borne Pathogens. Int.J.Curr.Microbiol.App.Sci. 6(6): 3132-3149. doi: https://doi.org/10.20546/ijcmas.2017.606.370 